\title{
QUESTIONS OF METROLOGICAL ASSURANCE OF THE RESULTS OF THE GLUTEN CONTENT DETERMINATION IN FOODSTUFFS
}

\author{
KRASHENININA M.P.
FSUE «URAL SCIENTIFIC RESEARCH INSTITUTE FOR METROLOGY», Ekaterinburg
The address: Russia, 620075, Ekaterinburg, Krasnoarmejsky, 4, Tel.: (343) 350-60-63, E-mail: krasheninina m@uniim.ru

The main regulatory documents that establish safety requirements for specialty food products intended for patients with celiac disease are considered in this work. Short description of the immunoenzyme method is presented. A review of the world experience in the development of certified reference materials of gluten (gliadin) is given. The approach used for certification of the reference materials of gliadin (gluten) sample designed for metrological assurance of the results of the gluten content determination in foodstuffs in the territory of the Russian Federation is presented. The first results of creating of gliadin certified reference material by determination of nitrogen mass fraction with subsequent recalculation of the obtained value to the protein content are considered. Nitrogen mass fraction is measured with the help of The State secondary measurement standard of mass fraction and mass (molar) concentration of components in liquid and firm substances and materials by volumetric titration (GVET 176-1-2010). Nitrogen-to-protein conversion factor is obtained on the basis of determination of gliadin aminoacidic composition with the use high performance liquid chromatography with mass-selective detector.

In accordance with the Codex Alimentarius Commission document [1], gluten is defined as the protein fraction of wheat, rye, barley, oats or their hybrids and derivatives from this protein fraction that may be intolerable by some people and are insoluble in water and $0.5 \mathrm{M}$ solution of sodium chloride. Gluten consists of prolamines and glutelins. Prolamins is a protein fraction of gluten, extracted by $40-70 \%$ solution of ethyl alcohol. Prolamins of wheat are gliadin, rye prolines are sekaline, barley prolamines are hordein, prolamin oats are avenin. The content of gluten directly depends on the content of prolamine. Gluten content control in food products plays a key role in ensuring the safety of food intended for patients with celiac disease that is a chronic, progressive, hereditary disease characterized by persistent gluten intolerance to cereals with the development of atrophy of the small intestinal mucosa and associated malabsorption syndrome. According to international organizations, up to $1 \%$ of the world's population suffers from this disease [2]. The only way to treat celiac disease and prevent its complications is a strict and life-long gluten-free diet. Requirements for the content of gluten in certain types of specialized food products are established in the international documents of Codex Standard 118 [1] and ALINORM 08/31/26 [3], prepared by the Codex Alimentarius Commission of Nutrition and Food for special diets (CCNFSD). There is Technical Regulations "On the safety of certain types of specialized food products, including dietary curative and dietary preventive nutrition" [4] in the territory of the Customs Union.

According to the international document [5], ELISA is the recommended method for determination of gluten content in food ingredients and prepared foods. The choice in favor of the ELISA method was made in view of its specificity, sensitivity and suitability for routine analysis.

The ELISA method is based on an enzyme-linked immunoassay, in which the labeled antibodies to gliadin form a chemically strong complex that changes the color of the products of chemical reactions, followed by measurement of the absorbency. ELISA method is implemented in test systems produced by various manufacturers and based on the use of antibodies that were induced to various prolamine fractions or specific sequences that are toxic. Different test systems don't always give the same results for the determination of gluten content in the same food or food ingredients, as demonstrated, for example, in [6-8] and also in Figure 1. 


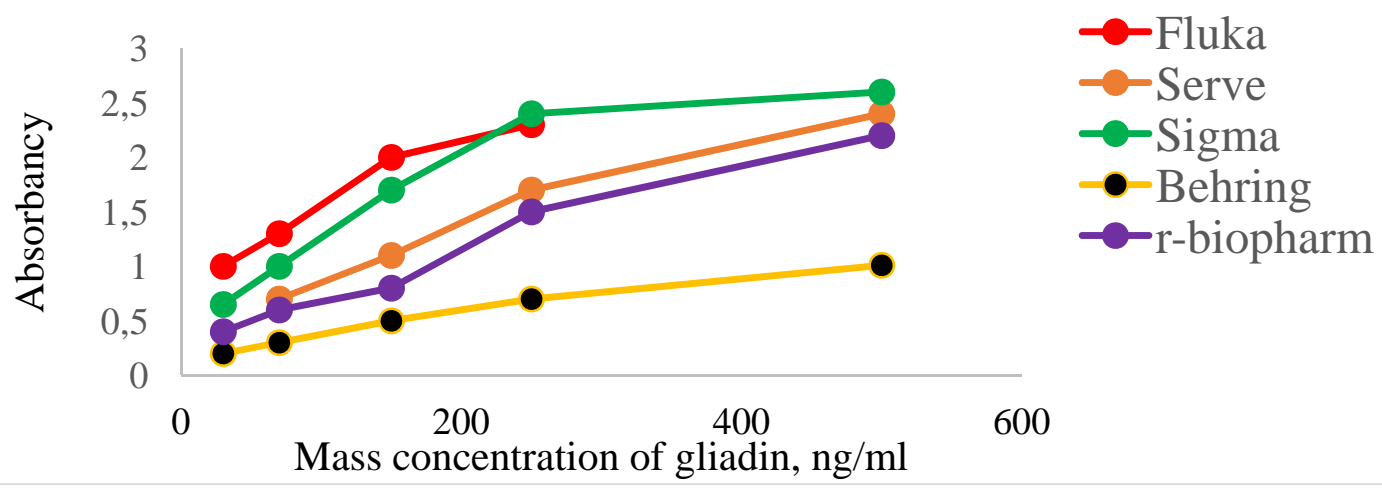

Fig.1 - Effect of the use of various reference materials for calibration of test systems

Up to date, the best-characterized reference material is the gliadin sample (further PWG-gliadin) developed by the Working Group on Prolamins and Toxicity (PWGAT). The extraction procedure and characterization of gliadin CRM is described in detail in [9]. PWG gliadin is a gliadin powder obtained by extracting gliadin from flour made from 28 of the most common European wheat varieties.

The Institute for Reference Materials and Measurements (IRMM, Belgium) initially approved the PWG-gliadin as a certified reference material, but soon withdrew this decision. In practice, it turned out that the creation of CRM that contains from 28 different varieties of wheat led to difficulties in measurements, to the high cost of CRM, and did not lead to a decreasing in the spread during measurements with the help of different test systems.

Thus, despite the large number of works devoted to this issue, to many manufacturers of test systems, the question of metrological assurance remains unresolved.

In this regard, FSUE "UNIIM" with the company "Hema" and the Institute of Physical Chemistry and Electrochemistry, Moscow has begun work for creation of CRM of gliadin. The starting material was wheat of solid flour. For gliadin getting the wheat flour was used. Gliadin was extracted from this flour with the help of $70 \%$ ethyl alcohol. Scheme for gliadin obtaining is shown in Figure 2.

Qualitative and quantitative analysis of gliadin sample was carried out at the Institute of Physical Chemistry and Electrochemistry. This analysis was conducted on a liquid chromatograph with mass-selective detector under reversed phase chromatography conditions with gradient elution. The results are shown in Table 1. The results presented in Table 1 were used to calculate the nitrogen-to-protein conversion factor.

Mass fraction of nitrogen in the sample of gliadin was determined with the help of the State secondary measurement standard of mass fraction and mass (molar) concentration of components in liquid and firm substances and materials by volumetric titration (GVET 176-1-2010). The validity of GVET 176-1-2016 usage is explained by the results of successful key comparisons CCQM-K130 "Mass fraction of nitrogen in glycine". 


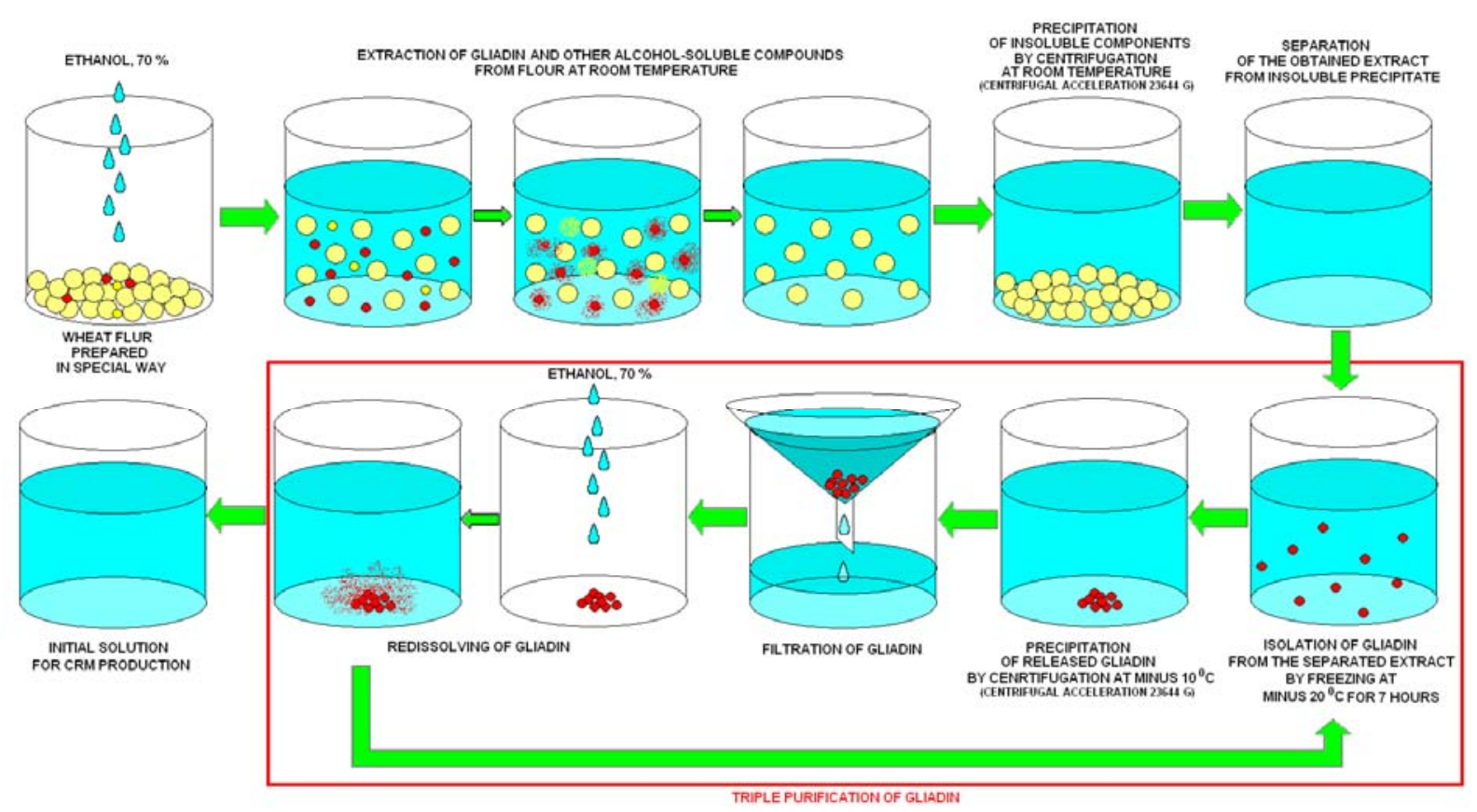

Figure 2 - Scheme of preparation of candidate material to CRM

Table 1 - Aminoacids content in the gliadin hydrolyzate obtained by HPLC/MS

\begin{tabular}{|c|c|c|c|c|c|c|c|c|c|c|}
\hline Aminoacids & $\begin{array}{l}\frac{0}{0} \\
\frac{\mathrm{T}}{0}\end{array}$ & $\begin{array}{l}\stackrel{0}{\frac{\mathscr{T}}{\mathbb{L}}} \\
\frac{\mathbb{\pi}}{<}\end{array}$ & $\stackrel{\stackrel{\oplus}{=}}{\stackrel{\underline{\sigma}}{>}}$ & 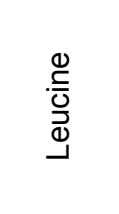 & 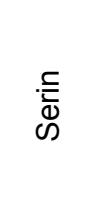 & 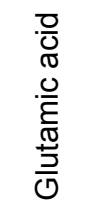 & 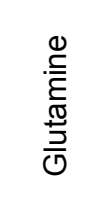 & 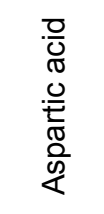 & $\begin{array}{l}\frac{0}{5} \\
\frac{5}{0} \\
\frac{\pi}{\pi} \\
\frac{0}{0} \\
\frac{0}{<}\end{array}$ & 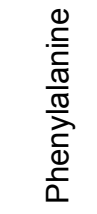 \\
\hline $\mathrm{C}, \mathrm{mg} / \mathrm{cm}^{3}$ & $<0,01$ & $<0,01$ & 1,2 & 124,4 & 0,16 & 9,3 & - & - & 5,4 & 4,2 \\
\hline$\%$, (mass) & $<0.003$ & $<0.003$ & 0.446 & 37.015 & 0.048 & 2.767 & - & - & 1.607 & 1.205 \\
\hline Aminoacids & 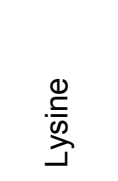 & 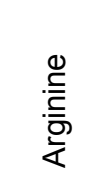 & 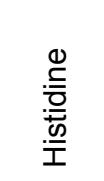 & 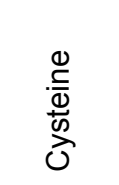 & $\begin{array}{l}\frac{1}{0} \\
\frac{2}{0} \\
\frac{0}{0} \\
\sum_{2}^{2} \\
1\end{array}$ & 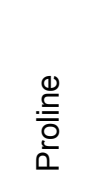 & 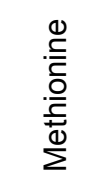 & 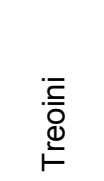 & \multicolumn{2}{|c|}{ 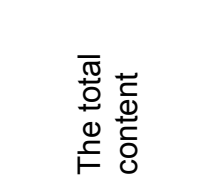 } \\
\hline $\mathrm{C}, \mathrm{mg} / \mathrm{cm}^{3}$ & - & 0,06 & 0,06 & - & - & 20,6 & $<0.01$ & 145.9 & \multicolumn{2}{|c|}{336,08} \\
\hline$\%$, (mass) & - & 0,018 & 0,018 & - & - & 6,129 & $<0.003$ & 43.412 & \multicolumn{2}{|c|}{100} \\
\hline
\end{tabular}

Characterized solution of gliadin in $70 \%$ alcohol was used to build a calibration curve for the test systems produced by the company "HEMA". This test system uses the principle of a two-site (sandwich) enzyme immunoassay. The calibration curve is shown in Fig. 3. 


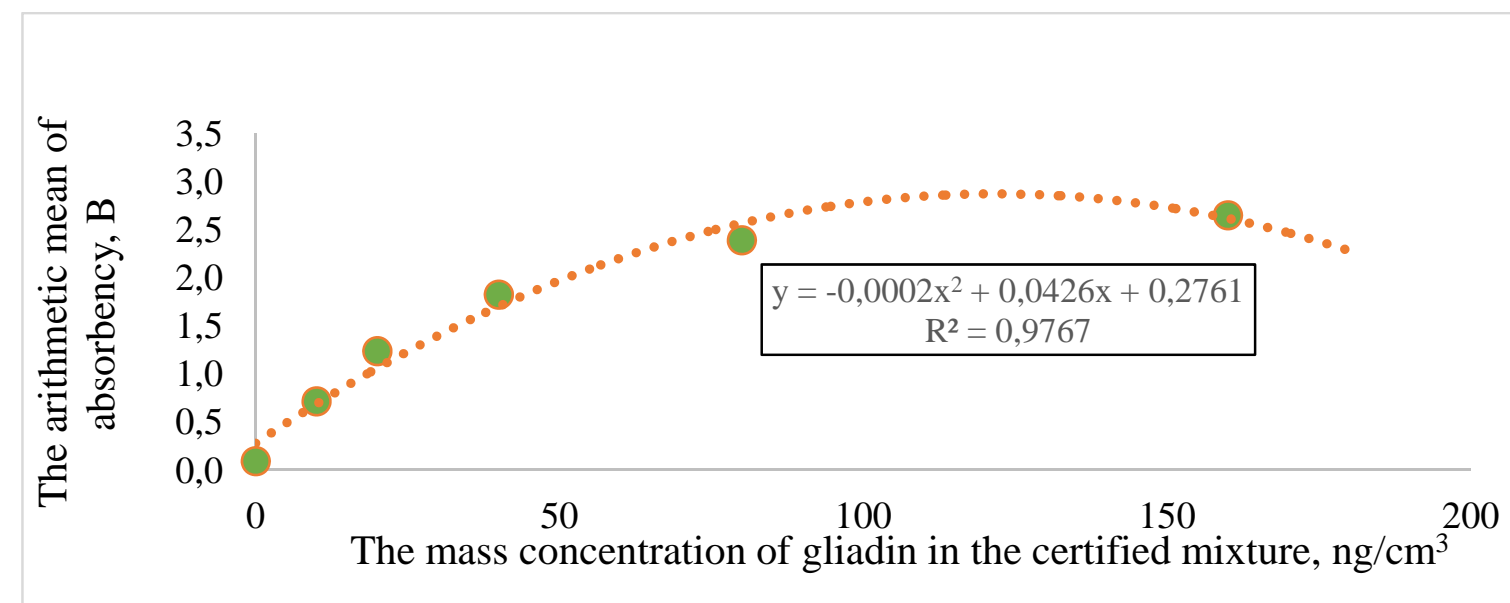

Figure 3 - Calibration curve obtained with the help of model solutions for the test system produced by the company "HEMA"

\section{Conclusions}

1. Gliadin was obtained from wheat flour by repeated extraction with $70 \%$ alcohol.

2. The Aminoacids composition of the gliadin solution was determined by the HPLC/MS method. The results of this experiments allowed to estimate the nitrogen-to-protein conversion factor.

3. Nitrogen mass fraction in the gliadin alcohol solution was determined with the help of GVET 176-1-2010 having confirmed calibration and measurement capabilities in the international BIPM database, that ensures the traceability of measurements of the mass fraction of nitrogen (gliadin protein) to SI units.

4. The prepared candidate material to CRM was tested for calibration of the test system produced by the company "HEMA". Preliminary accuracy characteristics for this test system are obtained.

\section{References}

1. Codex Alimentarius. 1979 (adopted 1979; amended 1983 and 2015; revised 2008). Standard 118-1979. Standard for Foods for Special Dietary Use for Persons Intolerant to Gluten. Food and Agriculture Organization of the United Nations and the World Health Organization, Rome.

2. Wieser H., Koehler P., Konitzer K. Celiac disease and gluten-multidisciplinary challenges and opportunities. Academic Press Elsevier, London, 2014.

3. Joint FAO/WHO Food Standards Programme. Codex Committee on Nutrition and Foods for Special Dietary Uses (2007a). Report of the 29th session, ALINORM 08/31/26.

4. Technical regulations of the Customs Union TR TS-027 - 2012 "On the safety of certain types of specialized food products, including dietary curative and dietary preventive nutrition", adopted by the decision of the Council of the Eurasian Economic Commission No. 34 of June 15, 2012.

5. Codex Committee of Methods of Analysis and Sampling. MAS/36 CRD/15. Report on the 36th session in Budapest, Hungary, on 23-27 February 2015.

6. Scherf K.A. Gluten analysis of wheat starches with seven commercial ELISA Test Kits - up to six different values // Food Anal. Methods. 2017. V. 10. P. 234-246.

7. Bugyi Z., Török K., Hajas L., Adonyi Z., Popping B., Tömösközi S. Comparative study of commercially available gluten ELISA kits using an incurred reference material // Qual Assur Saf Crop. 2013. V. 5. P. 79-87.

8. Török K., Hajas L., Horvath V., Schall E., Bugyi Z., Kemeny S., Tömösközi S. Identification of the factors affecting the analytical results of food allergen ELISA methods // Eur Food Res Technol. 2015. V. 241. P. 127-136.

9. Van Eckert R., Berghofer E., Ciclitira P.J., Chirdo F., Denery-Papini S., Ellis H.J., Ferranti P., Goodwin P., Immer U., Mamone G., Méndez E., Mothes T., Novalin S., Osman A., Rumbo M., Stern M., Thorell L., Whim A., Wieser H. Towards a new gliadin reference material - isolation and characterization // J Cer Sci. 2006. V. 43. P. 331-341. 